\title{
Prevalence of bronchial hyperresponsiveness and asthma in a rural adult population
}

\author{
A J WOOLCOCK, J K PEAT, C M SALOME, K YAN, S D ANDERSON, \\ R E SCHOEFFEL, G McCOWAGE, T KILLALEA
}

From the Department of Medicine, University of Sydney, and Department of Thoracic Medicine, Royal Prince Alfred Hospital, Camperdown, NSW, Australia

ABSTRACT The prevalence of bronchial hyperresponsiveness in adult populations is not known. To document its prevalence and distribution and to determine the factors associated with it, a random sample of the adult population of Busselton, Western Australia, was studied. Spirometric function, bronchial responsiveness to histamine, and atopic responses to skin prick tests were measured. Respiratory symptoms were determined by questionnaire. Data were obtained from 916 subjects. Of these, 876 underwent a histamine inhalation test and bronchial hyperresponsiveness to histamine (defined as a dose of histamine provoking a $20 \%$ fall in $\mathrm{FEV}_{1}$ equal to or less than $3.9 \mu \mathrm{mol}$ ) was found in $10.5 \%$. Another 40 subjects with poor lung function were tested with a bronchodilator and 12 were found to have bronchial hyperresponsiveness (defined as a greater than $15 \%$ increase in $\mathrm{FEV}_{1}$ ), making the total prevalence of bronchial hyperresponsiveness $11 \cdot 4 \%$. The prevalence of current asthma, defined as bronchial hyperresponsiveness plus symptoms consistent with asthma in the last 12 months, was $5.9 \%$. The distribution of bronchial hyperresponsiveness in the studied population was continuous. There was a significant association between it and respiratory symptoms, atopy, smoking, and abnormal lung function ( $p<0.001$ for all associations). There was no association with age, sex, or recent respiratory tract infection.

The prevalence of asthma in adult populations is largely unknown. Gregg ${ }^{1}$ has reviewed the published reports and pointed out that the lack of a definition and the different methods used to measure prevalence make comparisons of published studies difficult. Even so, it is likely that there is a higher prevalence in some populations than in others. For accurate descriptions of differences between populations a working definition of asthma and standard methods for documenting the prevalence are needed. Prevalence data, obtained with standard methods, might then be used as a basis for testing hypotheses relating to the nature and causes of asthma.

Since bronchial hyperresponsiveness appears to be a characteristic feature of asthma it seems sensible to include tests of bronchial responsiveness in prevalence studies. The distribution of bronchial responsiveness to histamine and the relationship of

Address for reprint requests: Dr AJ Woolcock, Department of Medicine, University of Sydney, Sydney, NSW 2006, Australia.

Accepted 7 October 1986 bronchial hyperresponsiveness to symptoms of asthma have not been described in adult populations.

To determine the prevalence and distribution of bronchial hyperresponsiveness in a rural Australian population we used a simple, rapid method for histamine inhalation tests. The prevalence and distribution were compared with the prevalence of respiratory symptoms, atopy, abnormal lung function, and recent upper respiratory tract infection.

\section{Methods}

The adult population of the shire of Busselton, situated $220 \mathrm{~km}$ south of Perth, Western Australia, is approximately 6000 . These adults have been asked to attend a health survey every three years since $1966{ }^{2}$ In November and December 1981, 3590 people attended the survey and one in four was assigned randomly to our study. The nature of the study was explained to each subject, and if consent was obtained subjects were entered into the sample.

QUESTIONNAIRE

Before the study each subject was sent a questionnaire 
on a range of health matters. Questions were taken from the Medical Research Council respiratory questionnaire. ${ }^{3}$ In addition, three questions were asked relating to wheeze or tightness in the chest, cough at night, and shortness of breath coming on at rest. Symptoms were considered to be consistent with asthma if the subject answered yes to one or more of the following questions: Have you ever wheezed or had chest tightness? Do you have a dry cough at night? Have you ever had shortness of breath coming on while you were at rest? Other respiratory symptoms recorded were shortness of breath during mild exertion and chronic productive cough. Other questions asked about previously diagnosed asthma and the time since symptoms last occurred. Symptoms were considered current if they had occurred within the previous 12 months.

On the day the subject attended the survey an additional, short questionnaire was administered which asked about recent upper respiratory tract infections and use of drugs for respiratory disorders.

HISTAMINE INHALATION TEST

Vitalograph spirometers (Vitalograph, UK) were used to record the maximal forced expiratory volume. At least two reproducible curves were obtained after each set of inhalations, and from these the $\mathrm{FEV}_{1}$ and the forced vital capacity (FVC) were recorded. Lung function was considered abnormal if the $\mathrm{FEV}_{1}$ was less than $70 \%$ of predicted or if the $\mathrm{FEV}_{1} / \mathrm{FVC}$ ratio was less than $80 \%$ of predicted. ${ }^{4}$

All subjects whose FEV 1 and FVC were more than $60 \%$ of predicted had a histamine inhalation test. Subjects who had taken an aerosol bronchodilator within six hours or an oral bronchodilator within 12 hours were asked to return for testing on another day. The test was carried out by the method developed in our laboratory for field studies. ${ }^{56}$ This method used well calibrated hand held DeVilbiss No 40 nebulisers from which discrete doses of histamine were delivered. After initial spirometric function saline was administered to exclude non-specific airway response to the inhalation of an aerosol or to the effort of the forced expirations, and to tutor the subject in the method of inhaling slowly with a short breath hold. Increasing doses of histamine diphosphate were then administered and the spirometric function was repeated 60 seconds after each dose. The doses given in this way were cumulative. The test required about 10 minutes for a person with non-reactive airways and about 15 minutes for a person with reactive airways. The per cent change in the $\mathrm{FEV}_{1}$ was plotted against the dose of histamine on a logarithmic scale and the dose, in $\mu \mathrm{mol}$, which caused a $20 \%$ fall $\left(\mathrm{PD}_{20} \mathrm{FEV}_{1}\right)$ was recorded.

Subjects with no respiratory symptoms and with normal lung function after the control inhalation of saline were given an abbreviated test in which the doses increased in fourfold increments. Subjects wit symptoms or with abnormal lung function were give? a test that started with the lowest dose and increasef in twofold increments. There is no difference betwee results obtained using either of these protocols. ${ }^{5} \mathrm{Th} \overline{\mathrm{\Phi}}$ test was stopped in all subjects if the $\mathrm{FEV}_{1}$ fell b\% $20 \%$ from the post-saline value or after a total cumu lative dose of $3.9 \mu \mathrm{mol}$ had been administered. $\vec{D}$ bronchodilator aerosol was given to help recover应 when required.

To examine the reproducibility of the histaming inhalation test 25 subjects were requested to return of the following day for a second test. Of these subjects, four had intermediate responsiveness and 21 ha@ bronchial hyperresponsiveness. The second test was performed in exactly the same way as the first test, bu not necessarily by the same technician. The degree of responsiveness found on the first occasion was not known by the technician at the time of the secon study.

\section{BRONCHODILATOR TEST}

A histamine inhalation test was not undertaken if subjects whose $\mathrm{FEV}_{1}$ or FVC was less than $60 \%$ of the predicted value. Instead, after the expirograms were recorded, either rimiterol $(1.0 \mathrm{mg}$ by metere aerosol) or salbutamol $(2.5 \mathrm{mg}$ by nebuliser) wa@ given. Rimiterol was used because it is a rapidl' acting $\beta_{2}$ adrenergic bronchodilator aerosol. The choice of bronchodilator depended on the severity of the airflow obstruction and on the ability of the subject to inhale from a metered aerosol. Subjects with an increase of more than $15 \%$ in FEV were considered to have increased bronchia responsiveness.

\section{SKIN TESTS}

Skin prick tests with 14 common allergens were performed as described by Pepys. ${ }^{7}$ The wheal size was recorded after 15 minutes as the long axis and its perpendicular. A positive response was defined as skin wheal diameter of at least $2 \mathrm{~mm}$ in both direc tions. Mild atopy was defined as one to three positive responses and severe atopy as four or more positive

PRACTICAL ASPECTS

Five technicians studied 922 subjects during a three week period. This required five sets of equipment including nebulisers and spirometers, all of whic were calibrated before and at regular intervals during the study. Each technician was able to study betwee four and six subjects in an hour.

DATA ANALYSIS

Normal responsiveness was defined as less than $10 \%$ change in $\mathrm{FEV}_{1}$ at the end of the test, intermediat? 
responsiveness as a $10-19 \%$ change, and bronchial hyperresponsiveness as a $\mathrm{PD}_{20} \mathrm{FEV}_{1}$ of $3.9 \mu \mathrm{mol}$ or less. Subjects were defined as having asthma if they had bronchial hyperresponsiveness plus symptoms consistent with asthma - that is, wheeze, night cough, or shortness of breath at rest-and the asthma was considered current if symptoms had occurred within the previous 12 months. Associations between variables were determined using $\chi^{2}$ analysis of contingency tables.

\section{Results}

Approximately $60 \%$ of the population of the shire attended the survey; 922 subjects were randomly allocated to our sample and they ranged in age from 18 to 88 years. The age and sex distribution of the sample group was not different from that of the total survey group (table 1). Furthermore, there were no differences in smoking history or occupation between the sample group and the survey group. The age distribution of the non-attenders is known and was not different from the survey group; however, there is no information relating to the state of health of the nonattenders. We could not obtain satisfactory lung function data from six subjects, who were unable to perform reproducible forced expiratory manoeuvres. Their data were excluded from analyses, leaving a total of 916 subjects with complete data.

Figure 1 shows typical dose response curves from five subjects in the sample. The response of the subject with the most severe bronchial hyperresponsiveness is shown by A. The curves marked B, C, and D are from subjects with progressively less severe degrees of bronchial hyperresponsiveness and the one marked $\mathrm{E}$ is from a normal subject. The areas marked severe, moderate, mild, and intermediate are the ranges of severity obtained in previous clinical studies using the histamine inhalation test. ${ }^{58}$

The $\mathrm{PD}_{20} \mathrm{FEV}_{1}$ values obtained from the 25 subjects studied on two consecutive days were reproducible to within one doubling dose of histamine in all but three subjects (fig 2). In these three subjects the $\mathrm{PD}_{20} \mathrm{FEV}_{1}$ values on the second occasion were within two doubling doses of their first value. In

Table 1 Age and sex distribution of subjects in survey and sample groups

\begin{tabular}{llllll}
\hline $\begin{array}{l}\text { Age } \\
\text { group } \\
\text { (years) }\end{array}$ & \multicolumn{2}{l}{ Survey } & & \multicolumn{2}{l}{ Sample } \\
\cline { 2 - 3 } \cline { 5 - 6 } \cline { 5 - 6 } & Men & Women & & Men & Women \\
\hline Under 30 & 284 & 349 & 75 & 64 \\
$30-39$ & 296 & 370 & & 92 & 83 \\
$40-49$ & 273 & 320 & & 67 & 84 \\
$50-59$ & 327 & 391 & & 77 & 89 \\
$60-69$ & 350 & 429 & & 87 & 90 \\
70 and over & 267 & 284 & 62 & 52 \\
\hline
\end{tabular}

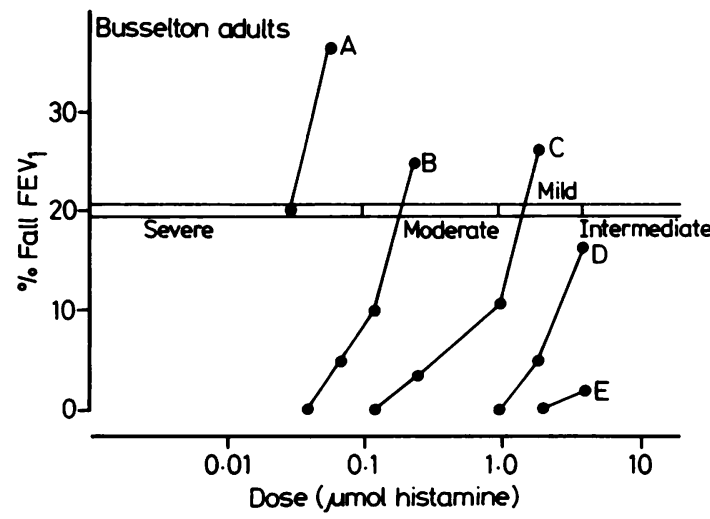

Fig 1 Typical dose response curves for inhaled histamine found in subjects in this study. Subject $A$ had the most severe degree of bronchial hyperresponsiveness; subjects $B$, $C$, and $D$ had progressively less severe bronchial hyperresponsiveness, and subject $E$ was normal. The line indicating the $20 \%$ fall in FEV shows the ranges for severe, moderate, and mild bronchial hyperresponsiveness defined from studies in the clinic.

the four subjects with intermediate responsiveness the dose response curves were extrapolated to obtain a $\mathrm{PD}_{20} \mathrm{FEV}_{1}$ value. None of the subjects fell into a different group-that is, bronchial hyperresponsiveness or intermediate responsiveness - on the second day.

To determine the prevalence of bronchial hyperresponsiveness subjects were divided into three

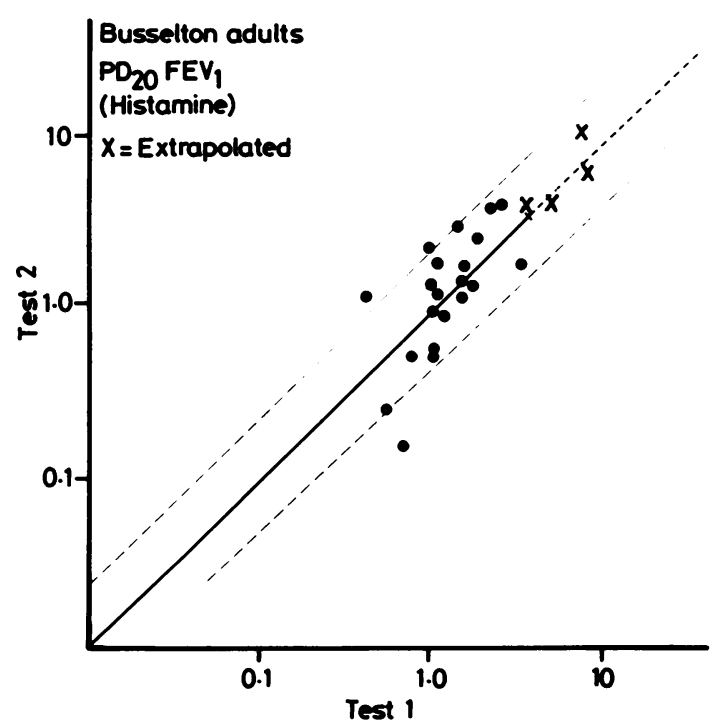

Fig $2 P D_{20} F E V_{1}$ values for 25 subjects treated on two different days. The solid line is the line of identity and the broken lines indicate one doubling dose. 
groups on the basis of their bronchial responsiveness (table 2). A total of 876 subjects were challenged with histamine, and $92(10.5 \%)$ of these had bronchial hyperresponsiveness. In addition, of the 40 subjects who had a bronchodilator test instead of a histamine challenge, 12 had a positive response and were therefore included in the group with bronchial hyperresponsiveness, giving 104 subjects, and increasing the prevalence of bronchial hyperresponsiveness to $11.4 \%$ of the sample. A further 92 subjects had intermediate responsiveness. Bronchial hyperresponsiveness was strongly associated $(p<0.001)$ with respiratory symptoms, atopy, smoking, and abnormal lung function. There was no association with age, sex, or recent upper respiratory tract infection.

Table 3 shows the strong association $(p<0.001)$ between bronchial hyperresponsiveness and diagnosed asthma, the use of asthma medications, and symptoms consistent with asthma-wheeze, shortness of breath coming on at rest, or nocturnal cough. A weaker association was found between bronchial hyperresponsiveness and shortness of breath on exertion $(p<0.01)$ and chronic productive cough $(\mathrm{p}<0.05)$.

Of 104 subjects with bronchial hyperresponsiveness, 71 reported having had one or more of the symptoms consistent with asthma. Thus the prevalence of asthma, defined as bronchial hyperresponsiveness, measured as a positive response to either histamine or bronchodilator, plus symptoms consistent with asthma at any time, was $7.8 \%$. Of these 71 subjects, 54 reported having had one or more of these symptoms in the previous 12 months, giving a prevalence of current asthma of $5.9 \%$,

Table 2 Number and clinical characteristics of subjects with bronchial hyperresponsiveness, intermediate responsiveness, and normal responsiveness

\begin{tabular}{|c|c|c|c|}
\hline & \multicolumn{3}{|l|}{ Responsiveness } \\
\hline & Hyperresponsive & Intermediate & Normal \\
\hline $\begin{array}{l}\text { No } \\
\text { Age (years) }\end{array}$ & 104 & 92 & 720 \\
\hline $\begin{array}{l}\text { (mean (SD)) } \\
\text { Sex (M/F) } \\
\text { Symptoms* }\end{array}$ & $\begin{array}{l}47 \cdot 9(16 \cdot 3) \\
41 / 63 \\
84\end{array}$ & $\begin{array}{l}50 \cdot 8(17 \cdot 8) \\
48 / 44 \\
62\end{array}$ & $\begin{array}{l}48 \cdot 8(17 \cdot 3) \\
368 / 352 \\
364\end{array}$ \\
\hline $\begin{array}{l}\text { Atopy } \\
\text { None } \\
\text { Mild } \\
\text { Severe }\end{array}$ & $\begin{array}{l}33 \\
18 \\
53\end{array}$ & $\begin{array}{l}40 \\
12 \\
40\end{array}$ & $\begin{array}{l}378 \\
114 \\
228\end{array}$ \\
\hline $\begin{array}{l}\text { Smoking } \\
\text { Never } \\
\text { Past } \\
\text { Current }\end{array}$ & $\begin{array}{l}49 \\
28 \\
27\end{array}$ & $\begin{array}{l}34 \\
26 \\
32\end{array}$ & $\begin{array}{l}400 \\
186 \\
135\end{array}$ \\
\hline $\begin{array}{l}\text { Abnormal lung } \\
\text { function }\end{array}$ & 38 & 11 & 65 \\
\hline $\begin{array}{l}\text { Respiratory tract } \\
\text { infection }\end{array}$ & 24 & 22 & 158 \\
\hline
\end{tabular}

*Any of: wheeze, night cough, shortness of breath at rest, shortness of breath on exertion, chronic productive cough.
Table 3 Number of subjects who answered yes to symptoms: at any time and degree of bronchial responsiveness

\begin{tabular}{|c|c|c|c|c|}
\hline & \multicolumn{4}{|c|}{ Responsiveness } \\
\hline & $\begin{array}{l}\text { Hyper- } \\
\text { responsive }\end{array}$ & Intermediate & Normal & $p$ \\
\hline $\begin{array}{l}\text { No } \\
\text { Wheeze } \\
\text { Short of }\end{array}$ & $\begin{array}{r}104 \\
64\end{array}$ & $\begin{array}{l}92 \\
31\end{array}$ & $\begin{array}{l}720 \\
162\end{array}$ & $<0.001$ \\
\hline $\begin{array}{l}\text { breath at rest } \\
\text { Night cough } \\
\text { Short of } \\
\text { breath on }\end{array}$ & $\begin{array}{l}15 \\
44\end{array}$ & $\begin{array}{r}6 \\
29\end{array}$ & $\begin{array}{r}32 \\
162\end{array}$ & $\begin{array}{l}<0.001 \\
<0.001\end{array}$ \\
\hline $\begin{array}{l}\text { exertion } \\
\text { Productive cough } \\
\text { Asthma diagnosed } \\
\text { Asthma treatment }\end{array}$ & $\begin{array}{l}19 \\
24 \\
39 \\
28\end{array}$ & $\begin{array}{r}6 \\
16 \\
11 \\
11\end{array}$ & $\begin{array}{l}58 \\
86 \\
33 \\
22\end{array}$ & $\begin{array}{l}<0.01 \\
<0.05 \\
<0.001 \\
<0.001\end{array}$ \\
\hline
\end{tabular}

Values for $p$ are the significance of $\chi^{2}$ values for the degree of association with bronchial hyperresponsiveness

In subjects with bronchial hyperresponsiveness to histamine the distribution of $\mathrm{PD}_{20} \mathrm{FEV}_{1}$ values appears to be continuous (figs 3-5). The severity of bronchial hyperresponsiveness was related to the presence of symptoms of asthma (fig 3). Of 92 subs jects with bronchial hyperresponsiveness to hista-mine, 62 reported having had one or more of the threg symptoms. At lower values of $\mathrm{PD}_{20} \mathrm{FEV}_{1}$, indicating more severe bronchial hyperresponsiveness, all sub $\frac{-}{\overline{0}}$ jects had had symptoms, whereas at higher values of $\mathrm{PD}_{20} \mathrm{FEV}_{1}$, indicating less severe bronchial hyper $\mathrm{D}$ responsiveness, the proportion of subjects without symptoms increased. The severity was also related te the presence of atopy. Atopy was present in $68 \%$ of subjects with bronchial hyperresponsiveness to hista

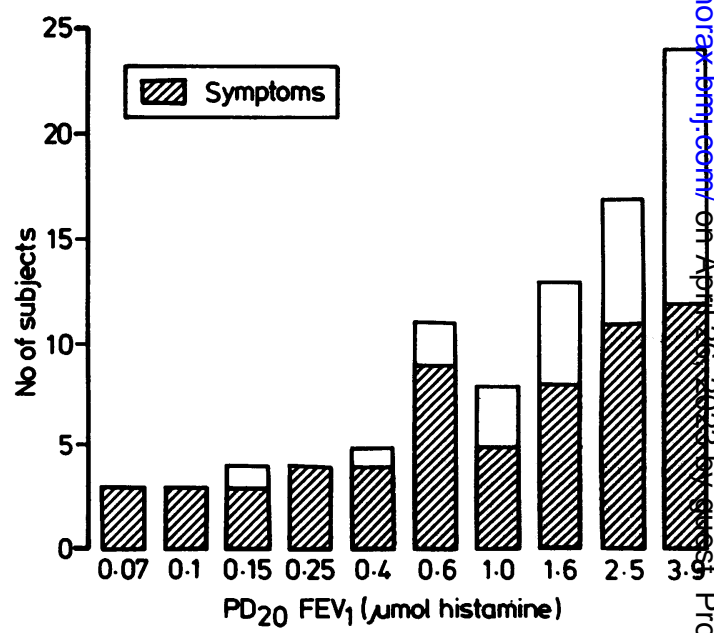

Fig 3 The distribution of bronchial hyperresponsiveness showing the number of subjects in each category of $P D_{20} F E V_{1}$ and the number with symptoms consistent with asthma at any time. The values for $P D_{20} F E V_{1}$ are the upper limits of each interval. 


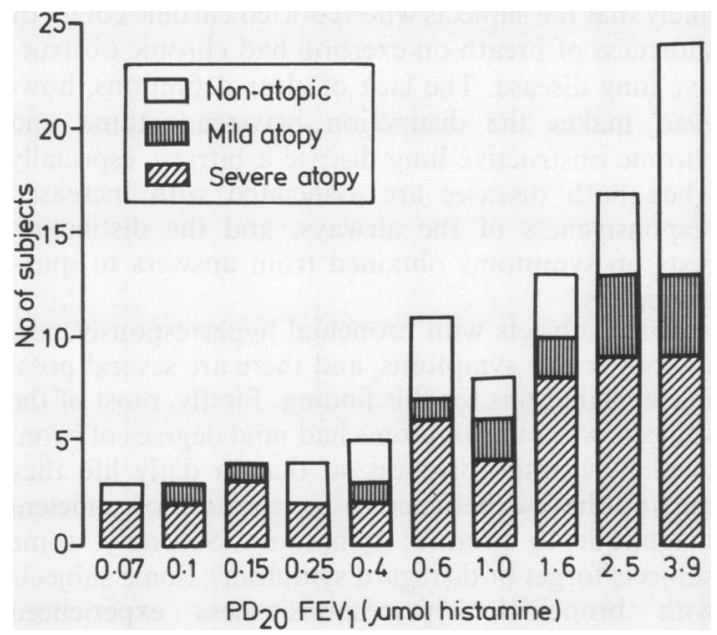

Fig 4 The distribution of bronchial hyperresponsiveness showing the number of subjects in each category of $P D_{20} F E V$, and the number with mild or severe atopy. The values for $P D_{20} F E V_{1}$ are the upper limits of each interval.

mine compared with $56 \%$ of the subjects with intermediate responsiveness and $48 \%$ of the subjects with normal responsiveness. At lower values of $\mathrm{PD}_{20} \mathrm{FEV}_{1}$ most of the subjects were atopic, but as the severity of bronchial hyperresponsiveness decreased the proportion of atopic subjects decreased (fig 4). The severity of bronchial hyperresponsiveness was similarly related to the presence of abnormal lung function (fig 5). Of the subjects with bronchial hyperresponsiveness to histamine, $28 \%$ had abnormal lung

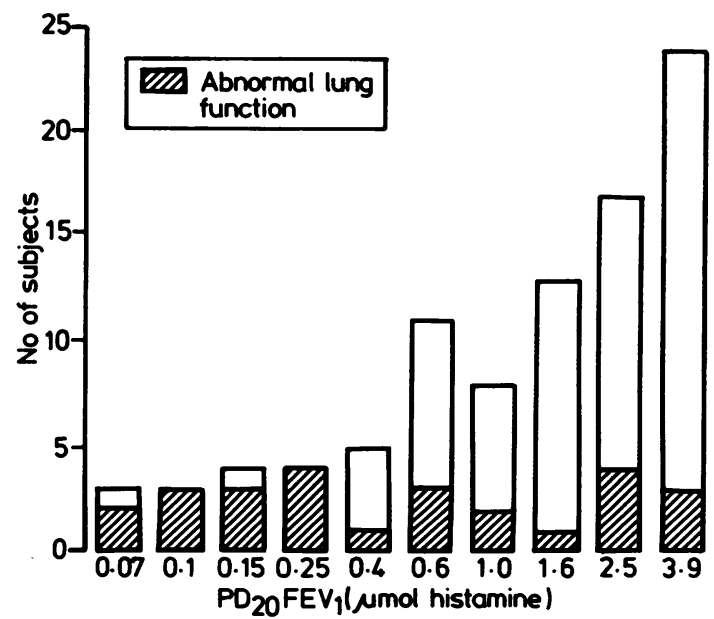

Fig 5 The distribution of bronchial hyperresponsiveness showing the number of subjects in each category of $P D_{20} F E V_{1}$ and the number with abnormal lung function. The values for $P D_{20} F E V_{1}$ are the upper limits for each interval. function compared with $12 \%$ with intermediate responsiveness and $8 \%$ with normal responsiveness. Of the subjects with a $\mathrm{PD}_{20} \mathrm{FEV}_{1}$ of less than $0.25 \mu \mathrm{mol}, 86 \%$ had abnormal lung function.

\section{Discussion}

The test of bronchial responsiveness to histamine proved to be feasible in this population study, and many expected problems did not arise. In particular, no unpleasant symptoms were experienced by the subjects apart from occasional mild hoarseness. The cooperation of the subjects was excellent; only five people refused to participate, and data were obtained from $99.5 \%$ of the subjects studied. The histamine inhalation test proved to be reproducible to within one doubling dose in most subjects, which compares well with the reproducibility of this method under laboratory conditions ${ }^{59}$ and with the reproducibility of other methods. ${ }^{1011}$

It is impossible to measure the entire distribution of bronchial responsiveness to histamine in a population. Firstly, some subjects have resting lung function that is too poor to allow the administration of histamine. Secondly, most subjects have no change in FEV $_{1}$ after $3.9 \mu \mathrm{mol}$ has been given, so that a $\mathrm{PD}_{20} \mathrm{FEV}_{1}$ cannot be recorded. In our laboratory doses of histamine up to $122 \mu \mathrm{mol}$ have failed to cause a $20 \%$ fall in $\mathrm{FEV}_{1}$ in many normal subjects. We consider that the group with no response to $3.9 \mu \mathrm{mol}$ of histamine had "normal" bronchial responsiveness, but we recognise that the distinction between normal responsiveness and hyperresponsiveness is necessarily arbitrary. The value obtained for $\mathrm{PD}_{20} \mathrm{FEV}_{1}$ depends on the type of test used, and the interpretation of the result depends on clinical experience with the test in subjects with known, well defined asthma. In clinical studies experience with this test has shown that subjects who have a $20 \%$ fall in FEV 1 at doses up to $3.9 \mu \mathrm{mol}$ have usually experienced symptoms consistent with a diagnosis of asthma and have required treatment. ${ }^{5}$ In this community study we defined bronchial hyperresponsiveness as a $\mathrm{PD}_{20} \mathrm{FEV}_{1}$ of less than $3.9 \mu \mathrm{mol}$ and, with our definition, the prevalence of hyperresponsiveness to histamine was $10.5 \%$ with an apparently continuous distribution (fig 3 ). If we had given a higher dose some subjects with intermediate responsiveness would have had a $20 \%$ fall, so that a definition of hyperresponsiveness as a $\mathrm{PD}_{20} \mathrm{FEV}_{1}$ of less than $8.0 \mu \mathrm{mol}$ (which we subsequently adopted) would have given a higher prevalence.

In subjects with poor lung function the response to bronchodilator aerosol was measured. The relation, however, between an increase in FEV after $_{\beta_{2}}$ adrenergic aerosol and a decrease in $F E V_{1}$ after histamine 
has not been established. It is usually accepted that an increase in $\mathrm{FEV}_{1}$ after bronchodilator indicates variable airflow obstruction consistent with asthma, ${ }^{12}$ but estimates of the size of the increase necessary to make the diagnosis vary. ${ }^{12}{ }^{13}$ We have accepted an increase of $15 \%$, the lowest value to have been suggested as clearly indicating reversibility. ${ }^{14}$ In the present study the group with very poor lung function was small, and if we had accepted a $20 \%$ increase in $\mathrm{FEV}_{1}$ the overall figure would have been little different. The prevalence of bronchial hyperresponsiveness in the 916 subjects studied increased from $10.5 \%$ to $11.4 \%$ when the subjects with a positive bronchodilator response were included.

Bronchial hyperresponsiveness was strongly associated with the presence of symptoms. The strongest associations were with symptoms considered to be consistent with asthma-wheeze, night cough, or shortness of breath at rest-and in the group with bronchial hyperresponsiveness the more severe the hyperresponsiveness the higher the proportion of subjects who reported having had these symptoms. This finding supports those of clinical and laboratory studies in which bronchial hyperresponsiveness appears to be a characteristic feature in subjects who have well documented asthma and in whom the severity is related to the severity of the symptoms. Wheeze and shortness of breath coming on at rest have long been recognised as typical symptoms of asthma and the importance of night cough has recently been recognised. ${ }^{15}$

In the absence of a universally accepted definition of asthma we have used a working definition in this study of bronchial hyperresponsiveness together with symptoms consistent with asthma. The questionnaire requested information about symptoms at any time in the past. The figure quoted for the prevalence of asthma $(7.8 \%)$ may underestimate the true cumulative prevalence because some subjects with past symptoms had normal bronchial responsiveness at the time of the study and were thus excluded. On the other hand, the figure for current asthma (5.9\%), which relies on bronchial hyperresponsiveness plus symptoms in the previous 12 months, is probably reliable.

Symptoms of chronic productive cough and of shortness of breath on exertion are more usually associated with a diagnosis of chronic obstructive lung disease than of asthma. ${ }^{16}$ Although there was a significant association between bronchial hyperresponsiveness and both chronic productive cough and shortness of breath on exertion, the association was not as strong as that between bronchial hyperresponsiveness and symptoms consistent with asthma. It has been shown ${ }^{1718}$ that an appreciable proportion of subjects with chronic obstructive lung disease have bronchial hyperresponsiveness, and it is likely that the subjects who reported chronic cough or: shortness of breath on exertion had chronic obstruc $\overrightarrow{\bar{s}}$ tive lung disease. The lack of clear definitions, however, makes the distinction between asthma and chronic obstructive lung disease arbitrary, especially when both diseases are associated with increasedo responsiveness of the airways, and the distinction rests on symptoms obtained from answers to ques tionnaires.

Some subjects with bronchial hyperresponsiveness did not report symptoms, and there are several poss $-\omega$ ible explanations for this finding. Firstly, most of the subjects without symptoms had mild degrees of bron $x$ chial hyperresponsiveness so that in daily life they may not have experienced a provocation of sufficien magnitude to produce symptoms. Secondly, somea subjects forget or disregard symptoms. Some subjectso with bronchial hyperresponsiveness experienced. tightness in the chest during the challenge and admit $\vec{z}$ ted to having had similar tightness previously, even though they did not report symptoms on the questionnaire. Thirdly, it is likely that bronchial hyper-o responsiveness can be transient. Several factors, such as respiratory infections ${ }^{19}$ and allergens exposure, ${ }^{20}$ are known to increase bronchial responsiveness tem-s porarily. We found no relation between bronchialo hyperresponsiveness and recent upper respiratoryo tract infection, and it is likely that respiratory infec- $\Omega$ tions play a relatively minor part.

There was an association between bronchial hyper- 3 responsiveness and the presence of atopy. This association has been found in a random population ${ }^{21}$ but? not in studies where the subjects were selected on the basis of symptoms or of atopy. ${ }^{223}$ Since asthma iso often regarded as an atopic disease, and the role of allergens in triggering attacks of asthma is wello described, an association between the prevalence of bronchial hyperresponsiveness and the prevalence of atopy is not surprising. It is, however, difficult to quantify the severity of atopy precisely using skin tests and this limits the value of detailed analysis of the relation.

There was a strong association between bronchialn hyperresponsiveness and both abnormal lung function and smoking. Recent evidence suggests that mosto subjects with airflow limitation $\left(\mathrm{FEV}_{\mathbf{1}} / \mathrm{FVC}\right.$ ratio less than $80 \%$ of predicted) have bronchial hyperresponsiveness and that there is a good correlationo between baseline $\mathrm{FEV}_{1}$ and $\mathrm{PD}_{20} \mathrm{FEV}_{1}{ }^{172425}$ Tay $=$ lor $e t a l^{25}$ showed that in smokers bronchial hyper - ? responsiveness is associated with an accelerated decline in $\mathrm{FEV}_{1}$, but it is not clear whether the hyper responsiveness is a factor accelerating the decrease in $\mathrm{FEV}_{1}$ in smokers or whether it is a consequence of airway narrowing resulting from smoking. In theo present study there were more current smokers in both the group with hyperresponsiveness (26\%) and? 
the group with intermediate responsiveness $(35 \%)$ than in the normal group $(19 \%)$. The proportion of subjects with abnormal lung function was increased in the group with bronchial hyperresponsiveness $(36 \%)$ but not in the group with intermediate responsiveness $(12 \%)$ compared with the normal group $(9 \%)$.

Studies that rely on data from questionnaires regarding symptoms are likely to overestimate the prevalence of asthma. Thirty seven per cent of the subjects in the sample reported respiratory symptoms, yet most of them had normal lung function and normal bronchial responsiveness. Of the $83(9 \%)$ subjects who reported a previous diagnosis of asthma, 33 had normal bronchial responsiveness and 25 of these did not have current symptoms. This group may have had asthma in the past. Among those with symptoms consistent with asthma and no bronchial hyperresponsiveness some may have had seasonal allergic asthma; however, all severely atopic subjects who reported symptoms consistent with asthma also had bronchial hyperresponsiveness. Longitudinal studies may help to define the cause of the reported symptoms.

Even when both bronchial responsiveness and symptoms consistent with asthma are recorded the measured prevalence of asthma is unlikely to be precise. Firstly, the definition of bronchial hyperresponsiveness is arbitrary and depends on the accuracy of the test. Secondly, data from questionnaires can never be entirely reliable. Thirdly, it is rarely feasible to study all subjects selected in a given population. In this study the prevalence of asthma is described in the study group only and may have been different in the non-attenders. Despite these reservations, the figure of $5.9 \%$ for the prevalence of current asthma in this population is probably accurate since it rests on a reliable test of bronchial responsiveness and the subject's memory for the previous 12 months only.

With the histamine inhalation test or questionnaires it is not possible to distinguish completely between asthma and chronic obstructive lung disease. In some subjects the two conditions coexist or asthma has become irreversible. Asthma and chronic obstructive lung disease might be distinguished if all subjects with abnormal lung function were given a bronchodilator test rather than a histamine test. Some subjects with asthma, however, may not respond to bronchodilator aerosol and may need treatment with corticosteroids before any reversibility can be shown. This procedure is beyond the scope of most epidemiological studies. Alternatively, all subjects with abnormal lung function could be studied on two occasions, once with a bronchoconstrictor and once with a bronchodilator, but this is not always prac- tical. In the future other provocation tests such as hyperventilation with dry air may be used, ${ }^{26}$ but this method is more difficult for field studies and requires a moderately high level of ventilation, which subjects with airflow limitation cannot always achieve.

The results of this study show that bronchial responsiveness can be measured reproducibly, rapidly, and without difficulty in populations and that the levels recorded correlate well with information about respiratory symptoms obtained by questionnaire. Until a definition for asthma is universally accepted we suggest that useful comparisons between populations may be made by measuring the prevalence of bronchial hyperresponsiveness and of symptoms consistent with asthma and determining the relation between them. In the future if provoking agents that are more specific for asthma are found the prevalence and distribution of bronchial hyperresponsiveness may be sufficient to estimate the prevalence of asthma.

We are grateful to the people of Busselton for their generous and helpful participation in this study. We thank Dr Kevin Cullen, Dr Gary Dowse, Margaret Brockman, and Barbara Thomson for their help with the organisation, and Kim.Wearne and Dr Norman Stenhouse for help with the management of data files. We also thank Dr Martin Stuckey and his coworkers, who were responsible for the skin testing from which the atopic state was determined.

This study was supported by grants from the National Health and Medical Research Council of Australia and the Asthma Foundation of NSW.

\section{References}

1 Gregg I. Epidemiological aspects. In: Clark TJH, Godfrey S, eds. Asthma. London: Chapman Hall, 1983:242-84.

2 Cullen KJ, Stenhouse NS. Welbourne TA, McCall MG, Curnow DH. Chronic respiratory disease in a rural community. Lancet 1968;ii:657-80.

3 Committee on Research into Chronic Bronchitis. Questionaire in respiratory symptoms and instructions for its use. London: Medical Research Council, 1966.

4 Morris JF, Koski WA, Johnson LC. Spirometric standard for healthy non smoking adults. Am Rev Respir Dis 1971;103:57-67.

5 Yan K, Salome CM, Woolcock AJ. Rapid method for measurement of bronchial reactivity. Thorax 1983; 38:760-5.

6 Woolcock AJ, Yan K, Salome CM. Methods for assessing bronchial reactivity. Symposium on cellular and neurogenic mechanisms in the nose and bronchi. Eur $J$ Respir Dis 1983;64:181-94.

7 Pepys J. Skin tests in diagnosis. In: Gell PGH, Coombs RRA, Lachmann PJ, eds. Clinical aspects of immunology. 3rd ed. Oxford: Blackwell Scientific, 1975:55-80. 
8 Woolcock AJ, Yan K, Salome CM, Sedgwick CJ, Peat JK. What determines the severity of asthma? Chest 1985;87(suppl):209-13.

9 Britton J, Mortagy A, Tattersfield A. Histamine challenge testing: comparison of three methods. Thorax 1986;41:128-32.

10 Juniper EF, Frith PA, Dunnett C, Cockcroft DW, Hargreave FE. Reproducibility and comparison of responses to inhaled histamine and methacholine. Thorax 1978;33:705-10.

11 Hariparsad D, Wilson N, Dixon C, Silverman M. Reproducibility of histamine challenge tests in asthmatic children. Thorax 1983;38:258-60.

12 Nicklaus TM, Burgin WW, Taylor JR. Spirometric tests to diagnose suspected asthma. Am Rev Respir Dis 1969;100:153-9

13 Skinner C, Palmer KNV. Changes in specific airways conductance and forced expiratory volume in one second after a bronchodilator in normal subjects and patients with airways obstruction. Thorax 1974; 29:574-7.

14 Committee Report. Criteria for the assessment of reversibility in airways obstruction. Report of the committee on emphysema. American College of Chest Physicians. Chest 1974;65:552-3.

15 Corrao WM, Braman SS, Irwin RS. Chronic cough as the sole presenting manifestation of bronchial asthma. $N$ Engl J Med 1979;300:633-7.

16 Anonymous. Terminology, definitions, and classification of chronic pulmonary emphysema and related conditions: a report of the conclusions of a Ciba Guest Symposium. Thorax 1959;14:286-99.

17 Yan K, Salome CM, Woolcock AJ. Prevalence and nature of bronchial hypperresponsiveness in subjects with chronic obstructive pulmonary disease. $\mathrm{Am} \mathrm{Rev}$
Respir Dis 1985;132:25-9.

18 DuToit JI, Woolcock AJ, Salome CM, Sundrum R, Black JL. Characteristics of bronchial hyperresponsiveness in smokers with chronic airflow limi-O tation. Am Rev Respir Dis 1986;134:498-501.

19 Empey DW, Laitenen LA, Jacobs L, Gold WM, Nadelo JA. Mechanisms of bronchial hyperreactivity in nor- $\widehat{\Phi}$ mal subjects after upper respiratory tract infection. $A m_{0}$ Rev Respir Dis 1976;113:131-9.

20 Cockcroft DW, Ruffin RE, Dolovich J, Hargreave FE. $\vec{\circ}$ Allergen induced increase in non-allergic bronchial reactivity. Clin Allergy 1977;7:503-13.

21 Cockcroft DW, Murdock KY, Berscheid BA. Relationship between atopy and bronchial $\overrightarrow{\times}$ responsiveness to histamine in a random population. Ann Allergy 1984;53:26-9.

22 Bryant DH, Burns MW. The relationship between bron- or chial histamine reactivity and atopic status. Clin Allergy 1976;6:373-81.

23 Woolcock AJ, Colman MH, Jones MW. Atopy and bronchial reactivity in Australian and Melanesianpopulations. Clin Allergy 1978;8:155-64.

24 Ramsdale EH, Morris MM, Roberts RS, Hargreave FE $\stackrel{2}{\sim}$ Bronchial responsiveness to methacholine in chronic $\vec{\bullet}$ bronchitis: relationship to airflow obstruction and cold air responsiveness. Thorax 1984;39:912-8.

25 Taylor RG, Joyce H, Gross E, Holland F, Pride NB. Bronchial reactivity to inhaled histamine and annuals rate of decline in $\mathrm{FEV}_{1}$ in male smokers and ex-产 smokers. Thorax 1985;40:9-16.

26 Welty ST, Weiss IB, Tager IA, et al. Relationship of airways responsiveness to cold air, cigarette smoking, and atopy to respiratory symptoms and pulmonary응 function in adults. Am Rev Respir Dis 1984; 130:198-203. 